\title{
WECN
}

Energy research Centre of the Netherlands

\section{A Nodal Pricing Analysis of the Future German Electricity Market}

\author{
Özge Özdemir, J. Sebastiaan Hers (ECN, The Netherlands),
}

Emily Bartholomew Fisher, Benjamin F. Hobbs (Johns Hopkins University, USA),

Gert Brunekreeft (Bremer Energie Institut, Germany)
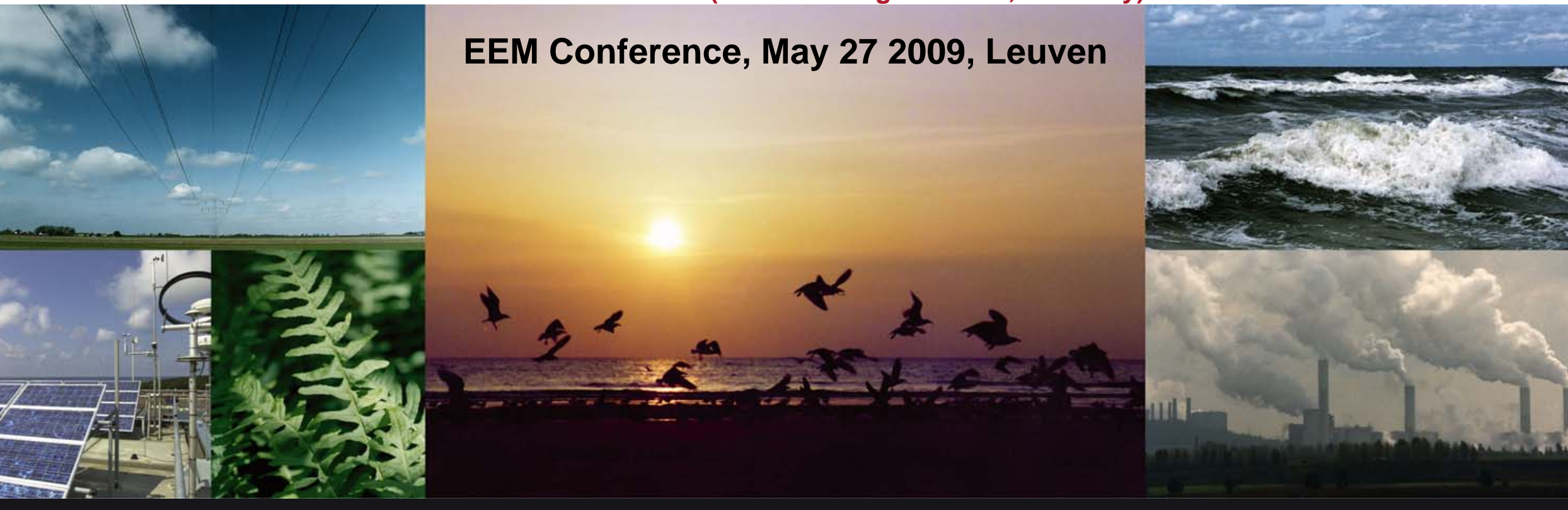


\section{Motivation}

Significant changes are expected to take place in German power market and its neighbouring countries until 2020:

- Expansion of new power generation capacities (e.g. coal, gas, and wind)

- Closures of old power plants (e.g. coal, nuclear)

- Expansion of interconnector capacities between national power markets and within German power grid

- Regulations in transmission system

(e.g., unbundling of TSO's, integration of EU markets) 


\section{Methodology}

Evaluation of the the impact of expected developments of new transmission and generation capacity in Germany and its neighboring countries on the future German power market in 2020 in terms of:

- Electricity market prices

- Congestion pattern and price differences within Germany

- Incentives of TSOs to invest in interconnection capacity 


\section{Tool: COMPETES Model}

- Short-run equilibrium (static) model of a transmissionconstrained EU power markets

- Geographical coverage: 20 EU countries

- Production system: individual power plants (ownership, fuel type, efficiency, availability, maximum output)

- Temporal coverage: 12 (demand) periods in a year

- Transmission Network: AC/DC lines and 3-Hub system (UCTE, Nordpool, and UK)

- physical transmission system based on linearized DC load flows between nodes

- auction-based transmission system between countries 


\section{Transmission Network}

- Covers 20 EU countries; each country as a single node

- Germany is represented by 10 regions

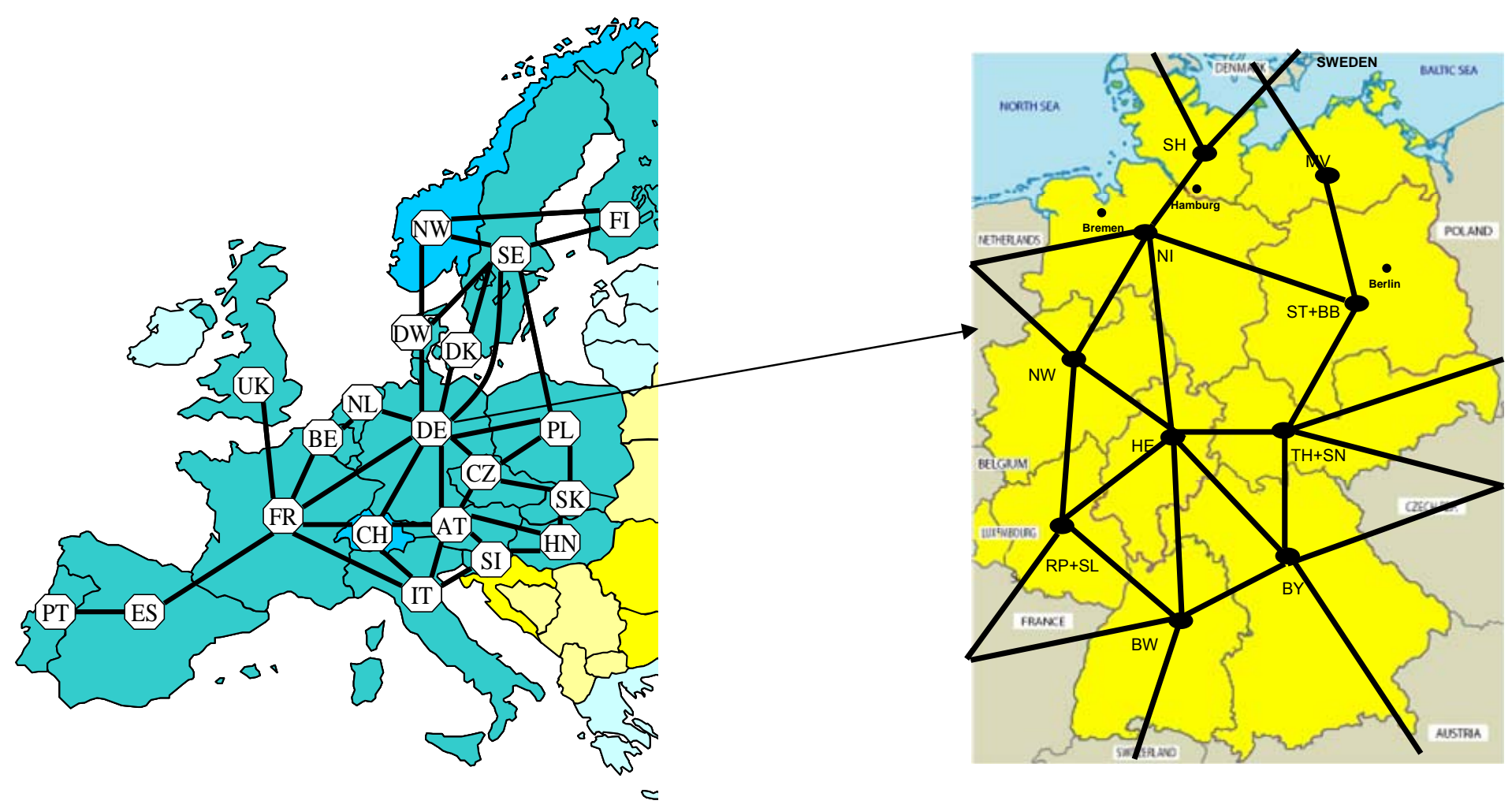




\section{Agents}

- Generators aiming to maximize profits

- Arbitrageurs aiming to maximize profits

- TSO's aiming to maximize the value of transmission

Oligopolistic generators

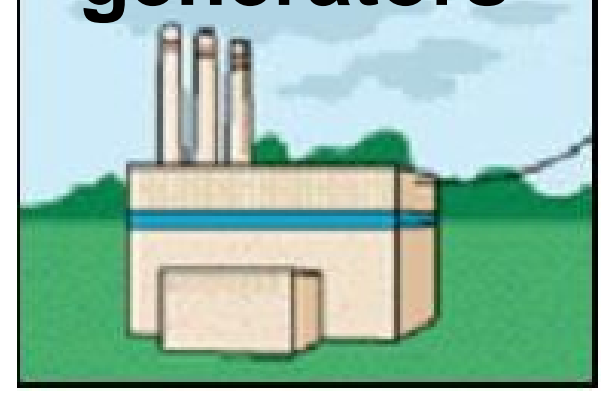

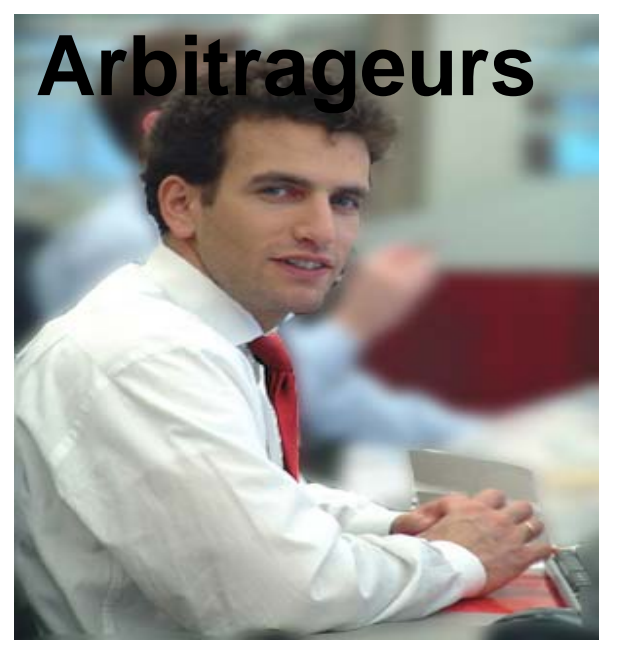

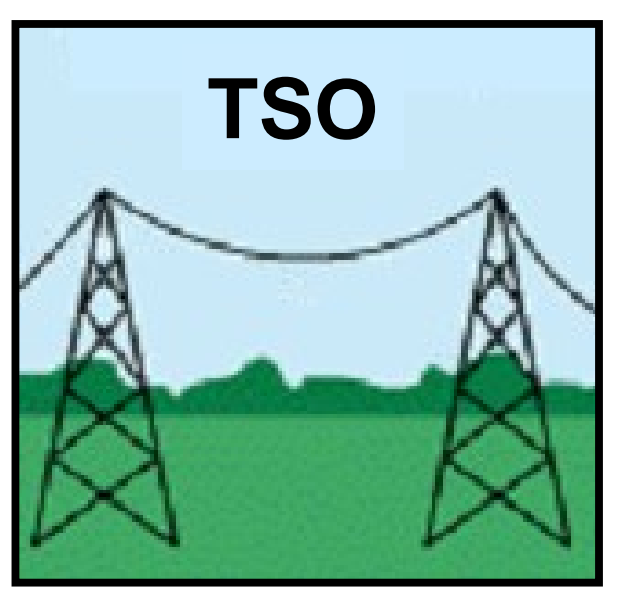




\section{Simulation runs for 2020}

$\square$ Country specific scenarios for Germany and neighboring countries on expansion of generation capacity

$\square$ Scenarios on expansion of transmission capacity

-EU interconnector expansion scenario by CESI study (2005)

- German network capacity expansion scenario by DENA study (2008)

$\square$ Fuel prices: Global Economy High Oil Price (GEHP) scenario (National scenario of the Netherlands)

$\square \mathrm{CO} 2$ price: 20 Euro/tonne 


\section{Overview of Scenarios}

\begin{tabular}{|l|c|c|}
\hline Low generation capacity in DE & $\begin{array}{c}\text { No transmission capacity } \\
\text { built in DE }\end{array}$ & Scenario 1 \\
\cline { 2 - 3 }$-14 \mathrm{GW}$ wind turbines in North \\
$-16 \mathrm{GW}$ nuclear is decommissioned & $\begin{array}{c}\text { Expected transmission } \\
\text { capacity built in DE } \\
\text { (by DENA) }\end{array}$ & Scenario 2 \\
\hline High generation capacity in DE & $\begin{array}{c}\text { No transmission capacity } \\
\text { built in DE }\end{array}$ & Scenario 3 \\
-Nuclear is not decommissioned & $\begin{array}{c}\text { Expected transmission } \\
\text { capacity built in DE } \\
\text { (by DENA) }\end{array}$ & Scenario 4 \\
\cline { 2 - 4 } & \multicolumn{2}{|c|}{} \\
\hline
\end{tabular}


Impact of wind turbine installations in the North: Low generation capacity scenarios

Scenario 1:LG-LT

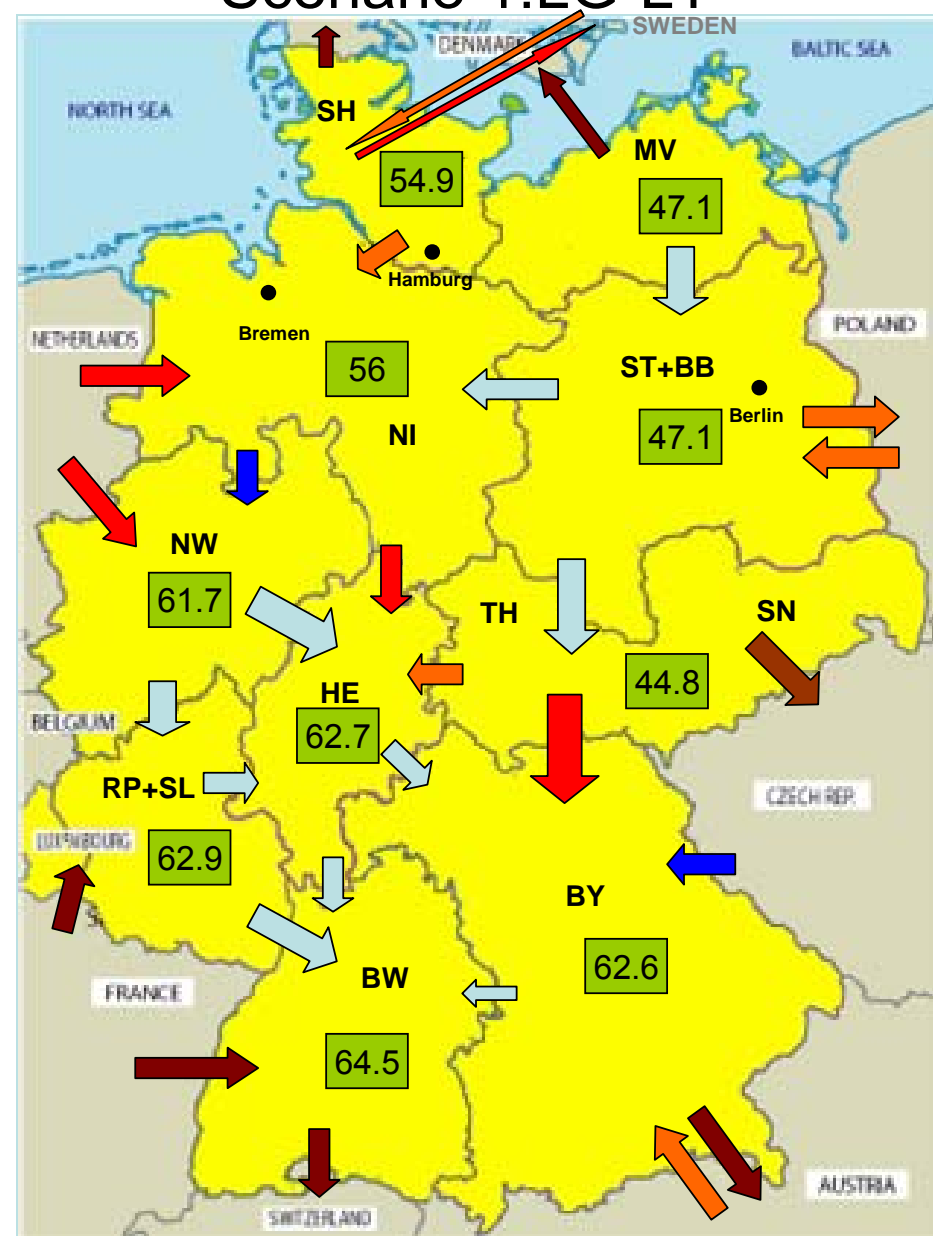

Scenario 2:LG-HT

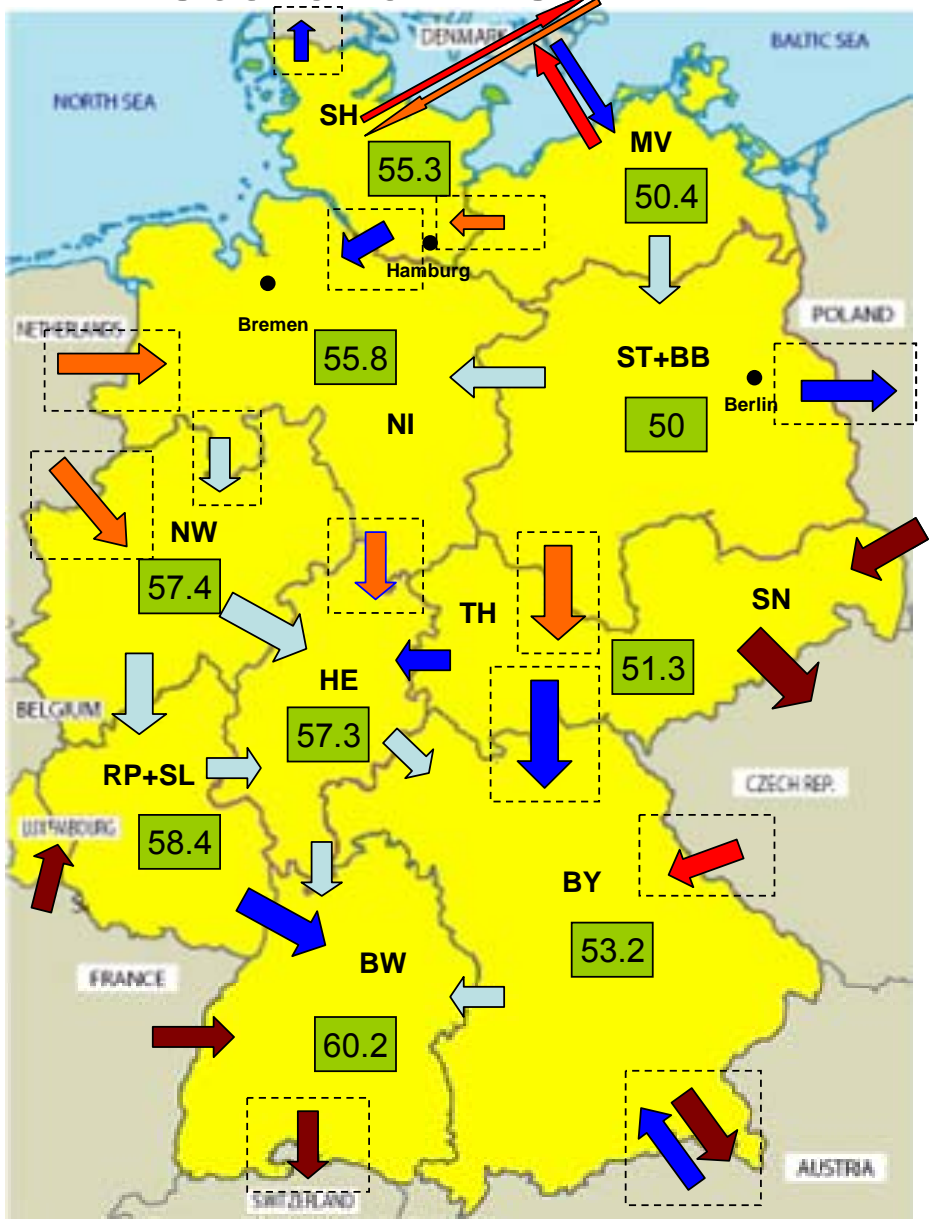


Impact of wind turbine installations in the North: High generation capacity scenarios

Scenario 3:HG-LT

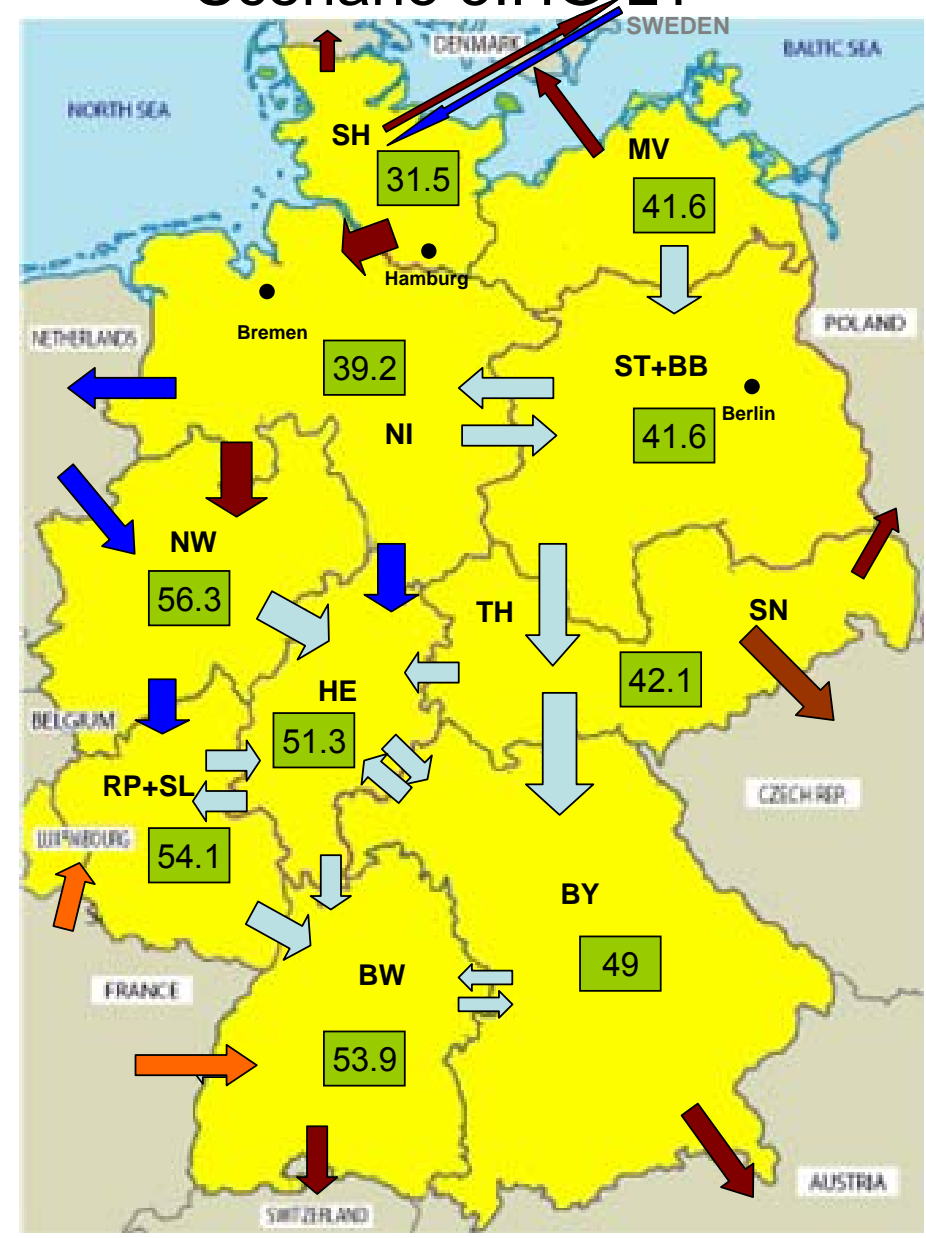

Scenario 4:HG-HT

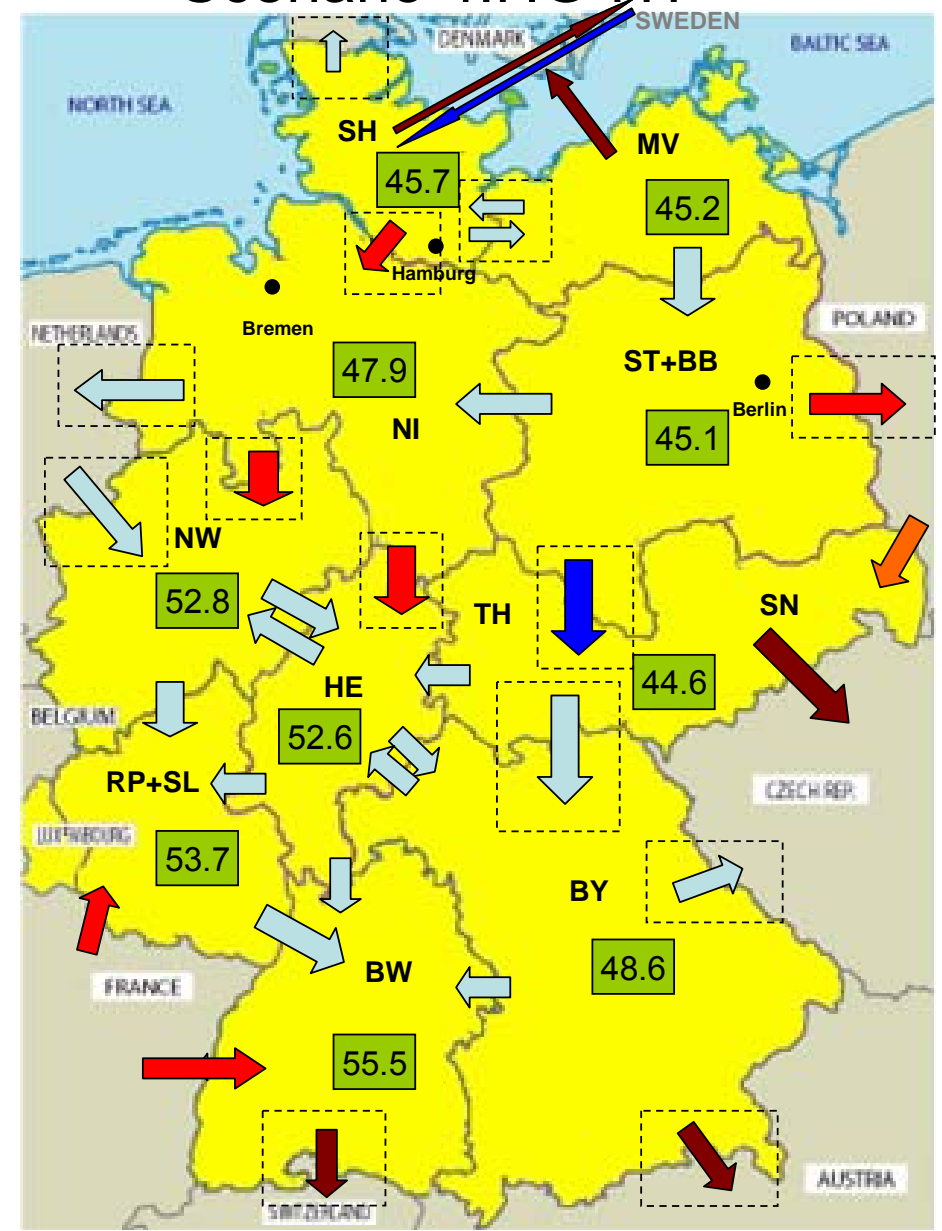




\section{Impact of nuclear decommissioning in the South (1)}

Scenario 3:HG-LT

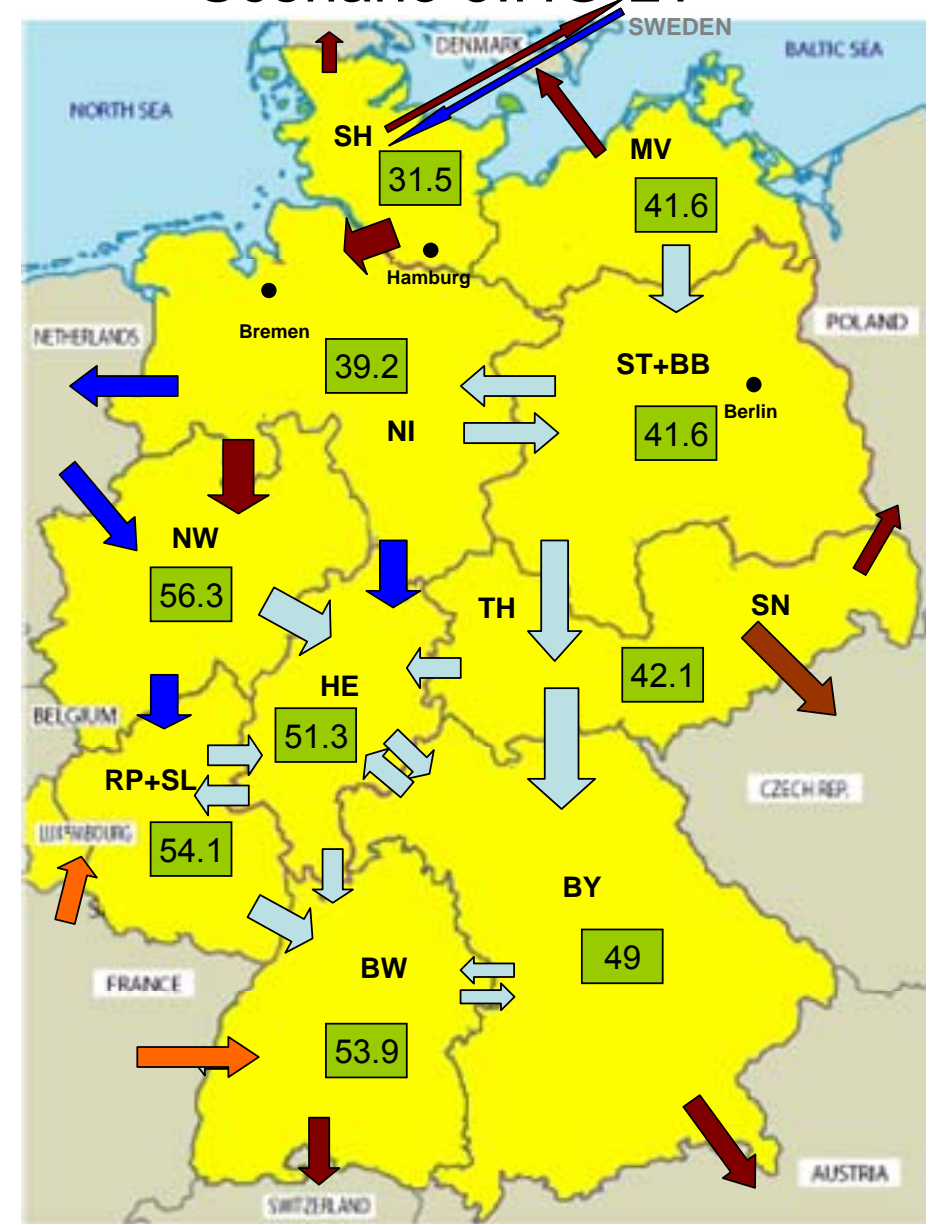

HG-LT (Nuclear is decommissioned)

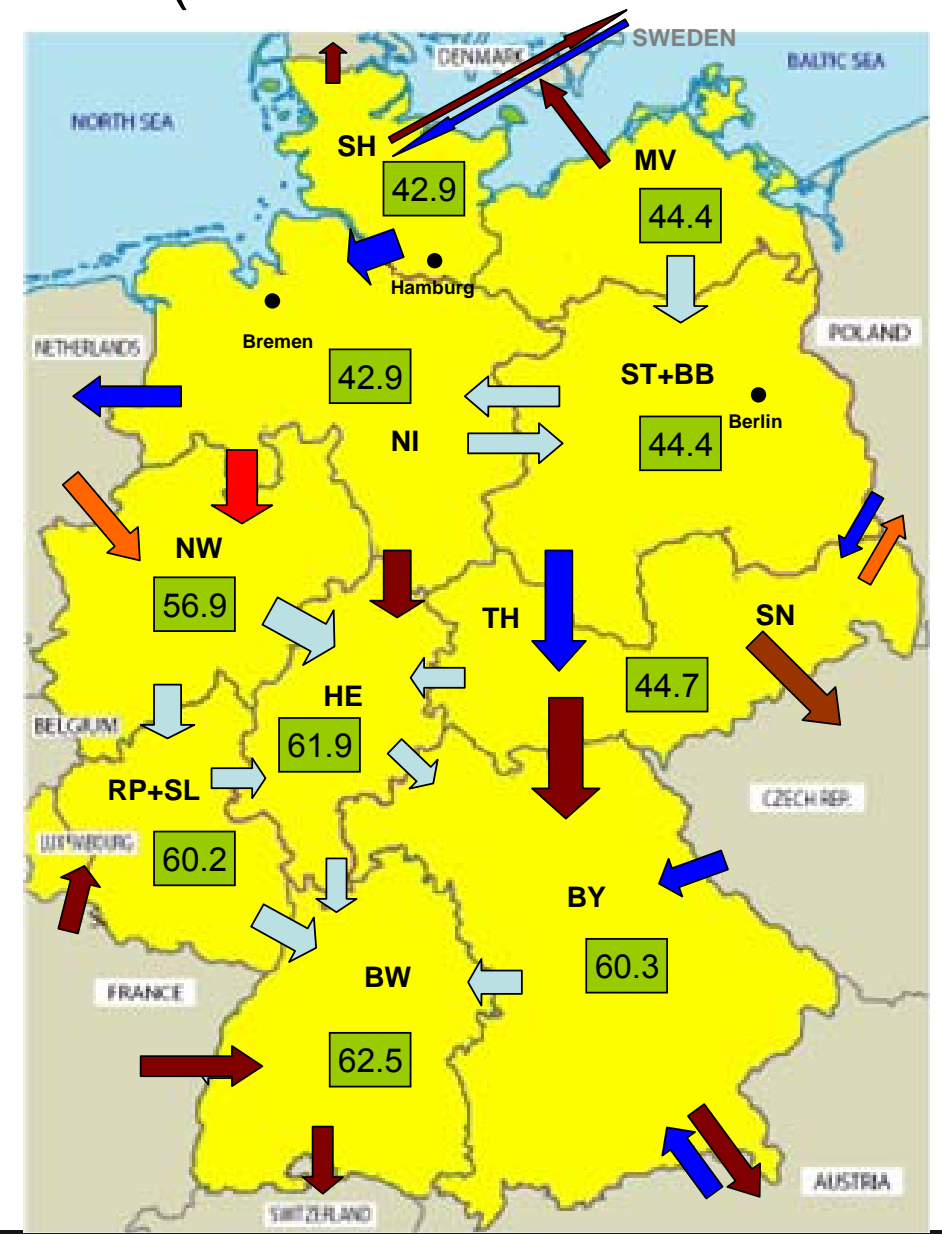




\section{Impact of nuclear decommissioning in the South (2)}

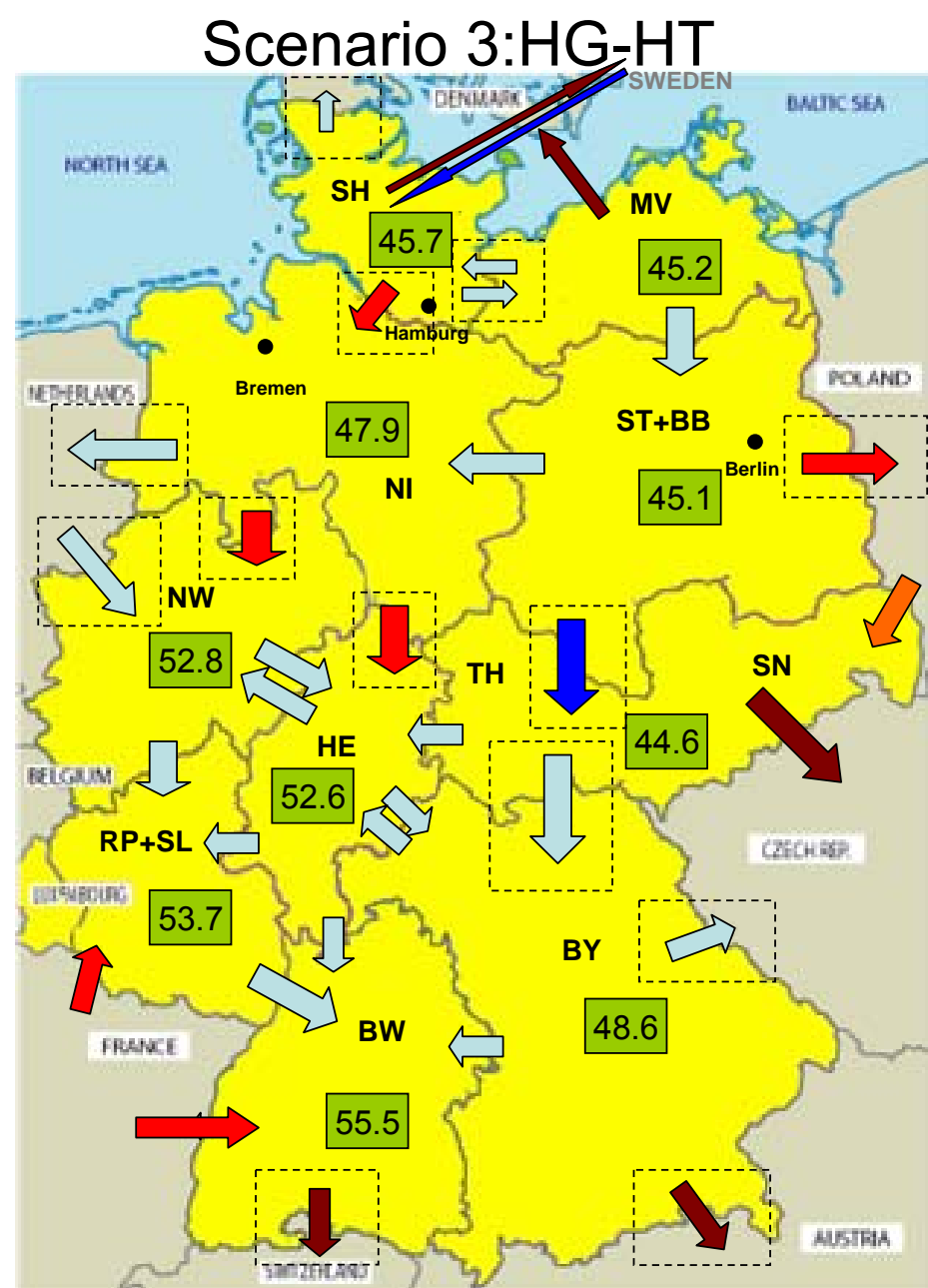

HG-HT (Nuclear is decommissioned)

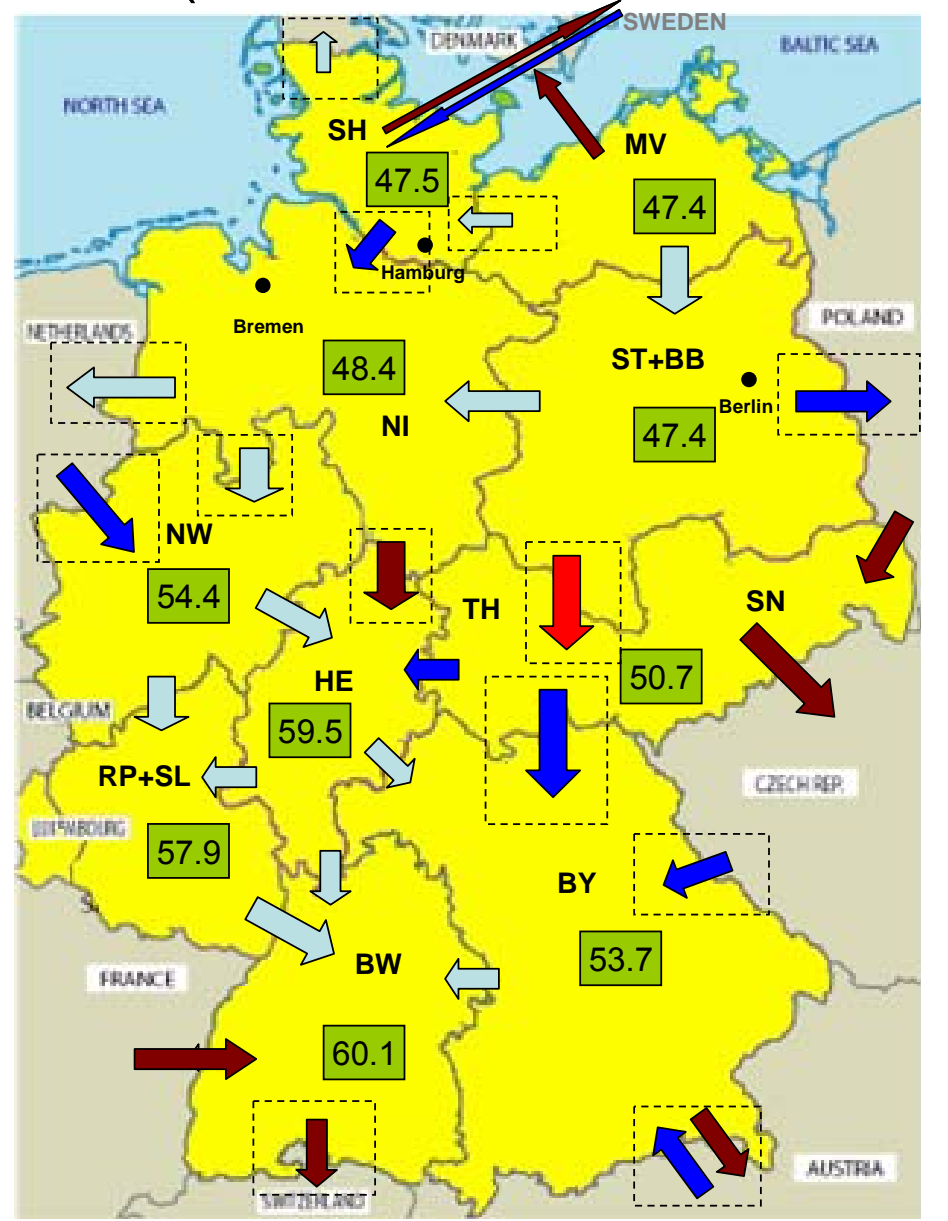




\section{Vertically Integrated Utilities vs Unbundled TSOs}

Assumptions for investment incentives: Congestion revenues (transmission surplus) are ring fenced to network investments.

$\square$ VIU: maximize its production surplus only

$\square$ Unbundled TSO: network charges would be regulated such that TSOs would be incented to make investments that increase overall market efficiency, no matter who benefits. (e.g., higher net surplus) 


\section{Investment Incentives}

Overview of Producer, Consumer, and Transmission Surplus (in MEuros)

\begin{tabular}{|c|c|c|c|c|c|c|}
\hline & \multicolumn{3}{|c|}{ Scenario 1} & \multicolumn{3}{|c|}{ Scenario 2} \\
\hline & PS & CS & TS & $\Delta \mathrm{PS}$ & $\Delta \mathrm{CS}$ & $\Delta(P S+C S+T S)$ \\
\hline DE & 13805 & 80398 & 855 & -1187 & 2027 & 91 \\
\hline $\begin{array}{l}\text { EU } 20 \\
\text { (excl. DE) }\end{array}$ & 90919 & 442756 & 2825 & -727 & 874 & 357 \\
\hline & \multicolumn{3}{|c|}{ Scenario 3} & \multicolumn{3}{|c|}{ Scenario 4} \\
\hline & PS & CS & TS & $\Delta \mathrm{PS}$ & $\Delta \mathrm{CS}$ & $\Delta(P S+C S+T S)$ \\
\hline DE & 14358 & 86474 & 1677 & 1864 & -779 & 1222 \\
\hline $\begin{array}{l}\text { EU } 20 \\
\text { (excl. DE) }\end{array}$ & 88680 & 445050 & 2311 & -2251 & 2545 & -475 \\
\hline
\end{tabular}




\section{Conclusions}

Future German power market:

- Congestion and nodal price differences may arise due to high wind turbine installations in the North

- Nuclear decommissioning in the South has an enhancing effect on congestion

- Single zone pricing may not be justifiable

- Unbundling is likely to stimulate investments in crossborder transmission capacity (if regulation ensures).

- In case Germany remains an export country, VIU's may also be incented to invest in cross-border transmission capacity. 


\section{References}

- CESI, IIT, ME, RAMBØLL A/S (2005): T E N-ENERGY- I n v e s t study.

- DENA (2008): Kurzanalyse der Kraftwerks-und Netzplanung in Deutschland bis 2020.

- BMWA, EWI, Prognos, "Studie - Energiereport IV - Die Entwicklung der Energiemärtkte bis zum Jahr 2030, Energiewirtschaftliche Referernzprognose", Bundesministerium für Wirtschaft und Arbeit, Referat Kommunikation und Internet/LP4, Berlin, May 2005.

- DEWI, E.ON Netz, EWI, RWE Net, VE Transmission, "Energiewirtschaftliche Planung für die Netzintegration von Windenergie in Deutschland an Land und Offshore bis zum Jahr 2020", Endbericht, Köln, February 2005.

- J.S. Hers, O. Ozdemir, "A Nodal Pricing Analysis of the Future German Electricity Market", ECN-E--09-013, Petten, forthcoming, 2009.

- B.F. Hobbs and F.A.M. Rijkers, "Strategic generation with conjectured transmission price responses in a mixed transmission pricing system-Part 1: Formulation," IEEE Transactions on Power Systems, vol. 19, no. 2, pp. 707-717, May 2004. 